\title{
Identification of prognostic microRNA candidates for head and neck squamous cell carcinoma
}

\author{
LIAN HUI, HUA WU, NING YANG, XING GUO and XUEJUN JANG \\ Department of Otolaryngology, The First Hospital of China Medical University, Shenyang, Liaoning 110001, P.R. China \\ Received December 11, 2015; Accepted January 11, 2016
}

DOI: $10.3892 /$ or.2016.4698

\begin{abstract}
The aim of the present study was to uncover potential prognostic microRNA (miRNA) markers in head and neck squamous cell carcinoma (HNSCC). miRNA expression profile and clinical data were obtained from The Cancer Genome Atlas (TCGA) database. Survival analysis was conducted by Kaplan-Meier method. Then, candidate prognostic miRNAs were screened via Cox proportional hazards regression analysis. Furthermore, target genes of miRNAs were predicted, and their interactions and functions were then analyzed. A total of 15 miRNAs were discovered to be significantly related to overall survival. Among them, miR-1251, miR-618 and miR-328 with $\mathrm{p}<0.05$ were potentially significant prognostic factors of HNSCC. In the protein-protein interaction (PPI) network, the target gene of miR-328, MAX, interacted with multiple genes. The target gene of miR-618, E2F1, interacted with genes such as $M A X, S M A D 3$ and $I G F 1$. Furthermore, the target genes of miR-618 (e.g. E2F1 and SMAD3), and the target genes of miR-328 (e.g. $M A X$ ) were significantly enriched in the functions of transcriptional regulation. The target gene of miR-1251, IGF1, was associated with functions such as signal transduction. The above miRNAs (miR-1251, miR-618 and miR-328) may be potential prognostic markers in HNSCC.
\end{abstract}

\section{Introduction}

Head and neck squamous cell carcinoma (HNSCC) accounts for the major proportion of head and neck cancers and is the sixth most common non-skin cancer worldwide (1). The high mortality rate of HNSCC results from poor prognosis and lack of reliable prognostic signatures. Thus, it is urgent to reveal more reliable prognostic markers to achieve better outcomes for HNSCC patients.

Correspondence to: Dr Lian Hui, Department of Otolaryngology, The First Hospital of China Medical University, 155 NanjingBei Street, Shenyang, Liaoning 110001, P.R. China

E-mail: huilianhl2@163.com

Key words: head and neck squamous cell carcinoma, microRNA, gene, survival analysis, prognostic marker
MicroRNAs (miRNAs) are small non-protein-coding RNAs of 22 nucleotides, and they play roles in various biological functions, such as cell growth, differentiation and the development of disease (2). Dysregulation of miRNAs is also closely related to the development, diagnosis and prognosis of many types of cancers including HNSCC (3). For instance, miR-218 inhibits cell migration and invasion by suppressing the expression of laminin-332 in HNSCC (4). By suppressing invadopodia activity, miR-375 impairs the tumor invasion of HNSCC and is implicated in the poor outcome of HNSCC $(5,6)$. Moreover, poorer overall survival of HNSCC has been found to be linked with the promoter methylation of miR-137 (7). In addition, overexpression of miR-205 is able to mediate HNSCC growth and E2F1 signaling (8). Although more and more studies have focused on uncovering miRNAs that are involved in HNSCC, few miRNAs have been identified as potential prognostic markers for HNSCC.

In the present study, to identify potential prognostic miRNA markers for HNSCC, miRNA expression profile and clinical data of 397 HNSCC cases were obtained from The Cancer Genome Atlas (TCGA) database. Survival and Cox regression analyses were performed to identify the miRNAs that were potentially associated with the survival of HNSCC patients. Furthermore, target genes of those miRNAs were predicted and the functions of the target genes were analyzed. The results may provide new information for the further study of HNSCC, and the identified miRNAs may be used as prognostic markers for HNSCC, which may be useful to improve future clinical outcome of HNSCC.

\section{Materials and methods}

Data acquisition. The miRNA expression profiling and clinical data of HNSCC were obtained from the TCGA database (http://cancergenome.nih.gov/, the deadline of data downloading: July 20, 2014). The miRNA expression profiling data included a total of 513 cases, and they were produced by two platforms: BCGSC_IlluminaGA_miRNASeq (37 cases) and BCGSC_IlluminaHiSeq_miRNASeq (476 cases). The clinical data included 418 HNSCC cases. After data filtering, only cases with both miRNA expression profile and clinical survival data (397 cases) were retained for further analysis.

Survival analysis. The average expression value of each miRNA in the 397 cases was calculated, and the mean value 
Table I. Results of the Cox proportional hazard regression analysis.

\begin{tabular}{|c|c|c|c|c|c|}
\hline Factor & $\beta$ & HR & P-value & Lower $95 \%$ & Upper $95 \%$ \\
\hline Gender & 0.070 & 1.072 & 0.66 & 0.7878 & 1.459 \\
\hline Smoke & 0.194 & 1.214 & 0.19 & 0.9094 & 1.620 \\
\hline Alcohol & 0.089 & 1.093 & 0.55 & 0.8171 & 1.462 \\
\hline Clinical_M & 0.576 & 1.778 & 0.14 & 0.8218 & 3.848 \\
\hline Clinical_N & -0.049 & 0.952 & 0.32 & 0.8648 & 1.049 \\
\hline Clinical_T & 0.023 & 1.023 & 0.76 & 0.8829 & 1.186 \\
\hline Clinical_stage & 0.064 & 1.066 & 0.62 & 0.8269 & 1.374 \\
\hline hsa-mir-643 & -0.123 & 0.884 & 0.39 & 0.6676 & 1.171 \\
\hline hsa-mir-126 & 0.0000418 & 1.000 & 0.44 & 0.9999 & 1.000 \\
\hline hsa-mir-1251 & 0.293 & 1.341 & 0.01 & 1.0897 & 1.649 \\
\hline hsa-mir-521-2 & -0.001 & 0.999 & 1.00 & 0.2949 & 3.386 \\
\hline hsa-mir-618 & 0.204 & 1.226 & 0.01 & 1.0558 & 1.423 \\
\hline hsa-mir-502 & 0.0135 & 1.014 & 0.43 & 0.9799 & 1.048 \\
\hline hsa-mir-328 & 0.0147 & 1.015 & 0.02 & 1.0024 & 1.027 \\
\hline hsa-mir-193a & -0.001 & 0.999 & 0.05 & 0.9982 & 1.000 \\
\hline hsa-mir-1301 & -0.016 & 0.984 & 0.22 & 0.9595 & 1.010 \\
\hline hsa-mir-1231 & 0.775 & 2.170 & 0.09 & 0.8921 & 5.278 \\
\hline hsa-mir-548y & 0.275 & 1.317 & 0.06 & 0.9906 & 1.750 \\
\hline hsa-mir-519c & 0.068 & 1.070 & 0.60 & 0.8274 & 1.385 \\
\hline
\end{tabular}

$\beta$, regression coefficient; HR, hazard ratio. Lower $95 \%$ and upper $95 \%$ represent the lower limit and the upper limit of the confidence interval, respectively.

was set as the critical value. Then, the cases were divided into two groups according to the miRNA expression values higher or lower than the critical value. Furthermore, survival estimates were calculated by the Kaplan-Meier (KM) method and the log-rank test based on a survival package in $\mathrm{R}(9)$. Only the miRNAs with $\mathrm{p}<0.05$ were considered significant. The miRNAs that had a significant association with survival time were selected for subsequent analysis.

Cox regression analysis. The miRNAs having a significant impact on survival time and clinical survival data received Cox proportional hazards regression analysis (10) based on KMsurv package in R (11). Patients with a high risk score were considered to have poor survival. The miRNAs with $\mathrm{p}<0.05$ were chosen for further analysis.

Target gene prediction. The target genes of the miRNAs with $\mathrm{p}<0.05$ in the Cox regression analysis were obtained based on the databases of miRecords (http://c1.accurascience. com/miRecords/) (12) and MiRWalk (http://www.umm.uniheidelberg.de/apps/zmf/mirwalk/) (13). Only the regulatory relationships recorded at least in 3 of the databases including miRanda (14), MirTarget2 (15), PicTar (16), PITA (17) and TargetScan (18) were selected for further analysis.

Construction of protein-protein interaction (PPI) network for target genes. PPIs between target genes of the miRNAs were analyzed via the online database Search Tool for the Retrieval of Interacting Genes (STRING, http://string-db.org/) (19).
Then, target gene pairs with a combined score $>0.4$ were chosen to construct PPI networks, which were visualized using the Cytoscape software (http://www.cytoscape.org/) (20). In the network, a node represents a protein (gene), and lines represent the interactions of the proteins. The 'degree' of each node is equal to the number of nodes that interact with this node. The larger the degree is, the closer the connections with other nodes are.

Functional analyses of target genes. The Database for Annotation, Visualization and Integrated Discovery (DAVID; https://david.ncifcrf.gov/) was applied to investigate the Kyoto Encyclopedia of Genes and Genomes (KEGG) pathways of the target genes (21). $\mathrm{p}<0.05$ was chosen as the cut-off criterion.

To further investigate the function of the target genes, the GenCLip tool (22) was utilized to perform functional clustering for genes in the PPI network based on literature mining, and the cut-off criteria were $\mathrm{p}<1 \mathrm{E}-04$ and hit $\geq 9$. Additionally, pathway enrichment analysis was performed for the genes in the PPI network, based on the Gene Set Enrichment Analysis (GSEA) database (http://software.broadinstitute.org/ gsea/index.jsp). $\mathrm{p}<0.05$ was set as the cut-off criterion.

\section{Results}

Survival analysis. In total, expression values of 1,046 miRNAs were obtained from the TCGA database. Among the miRNAs, a total of 15 miRNAs were discovered to be significantly 


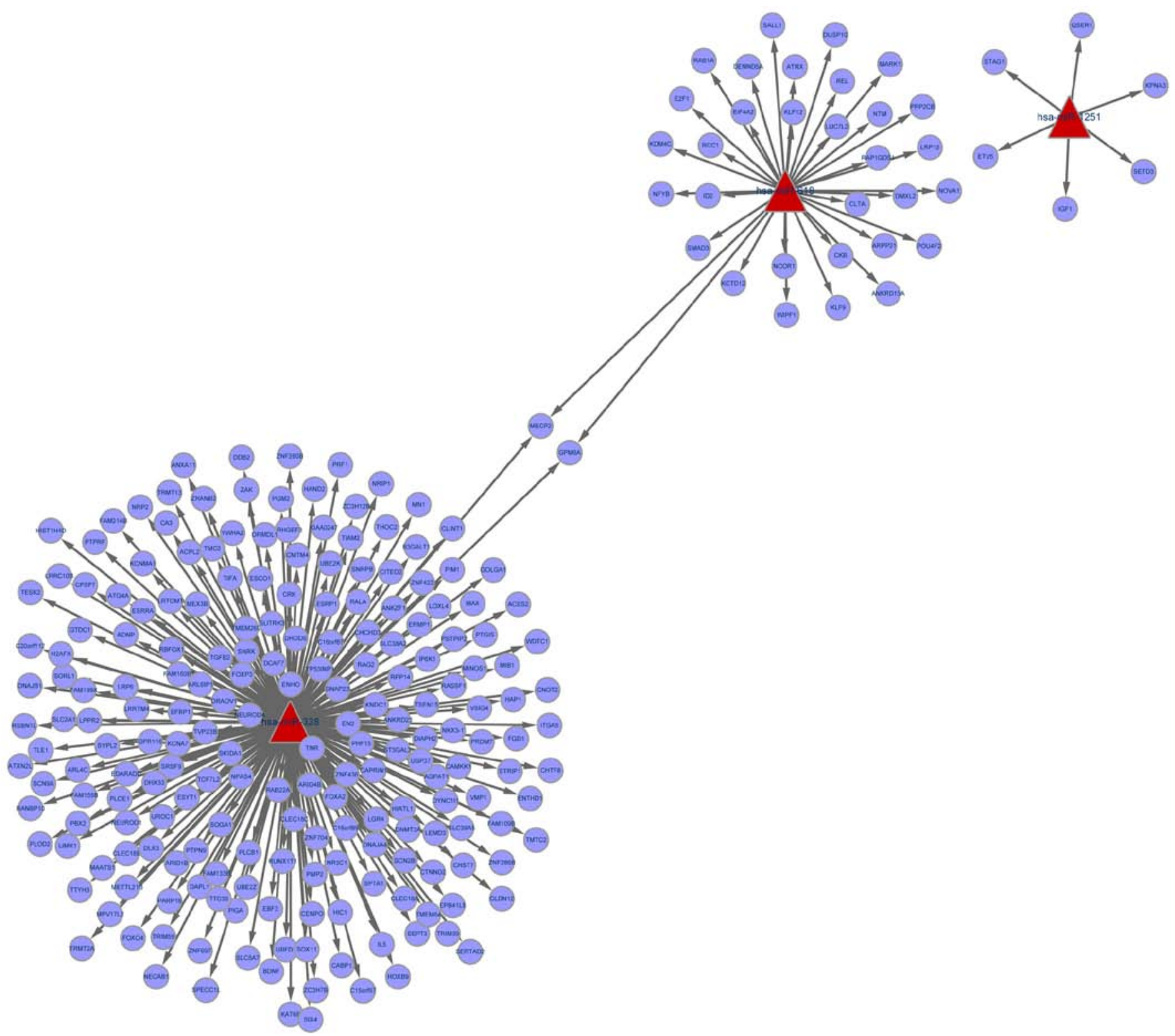

Figure 1. The regulatory network of microRNAs and target genes. Round nodes represent target genes, and trigonal nodes represent microRNAs.

related to survival time. Low expression of the 15 miRNAs was correlated with a higher survival rate based on the Kaplan-Meier survival analysis. Among the 15 miRNAs, miR-4292, miR-3685 and miR-1302.3 with no expression values in most of the samples were deleted and 12 miRNAs were finally screened.

Cox proportional hazards analyses. Cox proportional hazards analysis was performed with the clinical data [demographic characteristics, tumor-node-metastasis (TNM) classification, history of drinking and smoking] and the 12 miRNAs. Compared with the other clinical factors, miR-1251, miR-618 and miR-328 with $\mathrm{p}<0.05$ were significantly associated with risk factors of HNSCC (Table I).

Analysis of PPI network of target genes. A total of 245 genes were discovered to be regulated by miR-1251, miR-618 and miR-328. miR-328 modulated most of the genes, such as $M A X$.
miR-618 regulated genes such as E2F1 and SMAD3. miR-1251 targeted 6 genes such as IGFI (Fig. 1).

To further analyze the interactions of the target genes, an interaction network of the target gene was further constructed based on the STRING database. The PPI network was composed of 97 nodes and 112 lines (Fig. 2). Several genes had strong interactions with the other genes. For example, $M A X$ strongly interacted with 8 genes (e.g. E2F1); E2F1 interacted with $M A X, S M A D 3$ and $E 2 F 1$.

Functional analysis of target genes. To investigate the functions of the three miRNAs that were found to be potentially associated with risk factors of HNSCC, GO functional and KEGG pathway enrichment analyses of the target genes were performed. The target genes of hsa-mir-328 were mainly enriched in the GO terms of positive regulation of transcription (e.g. IL5 and FOXA2) and transcription activator activity (e.g. FOXA2 and $M A X$ ), as well as the pathways in cancer 


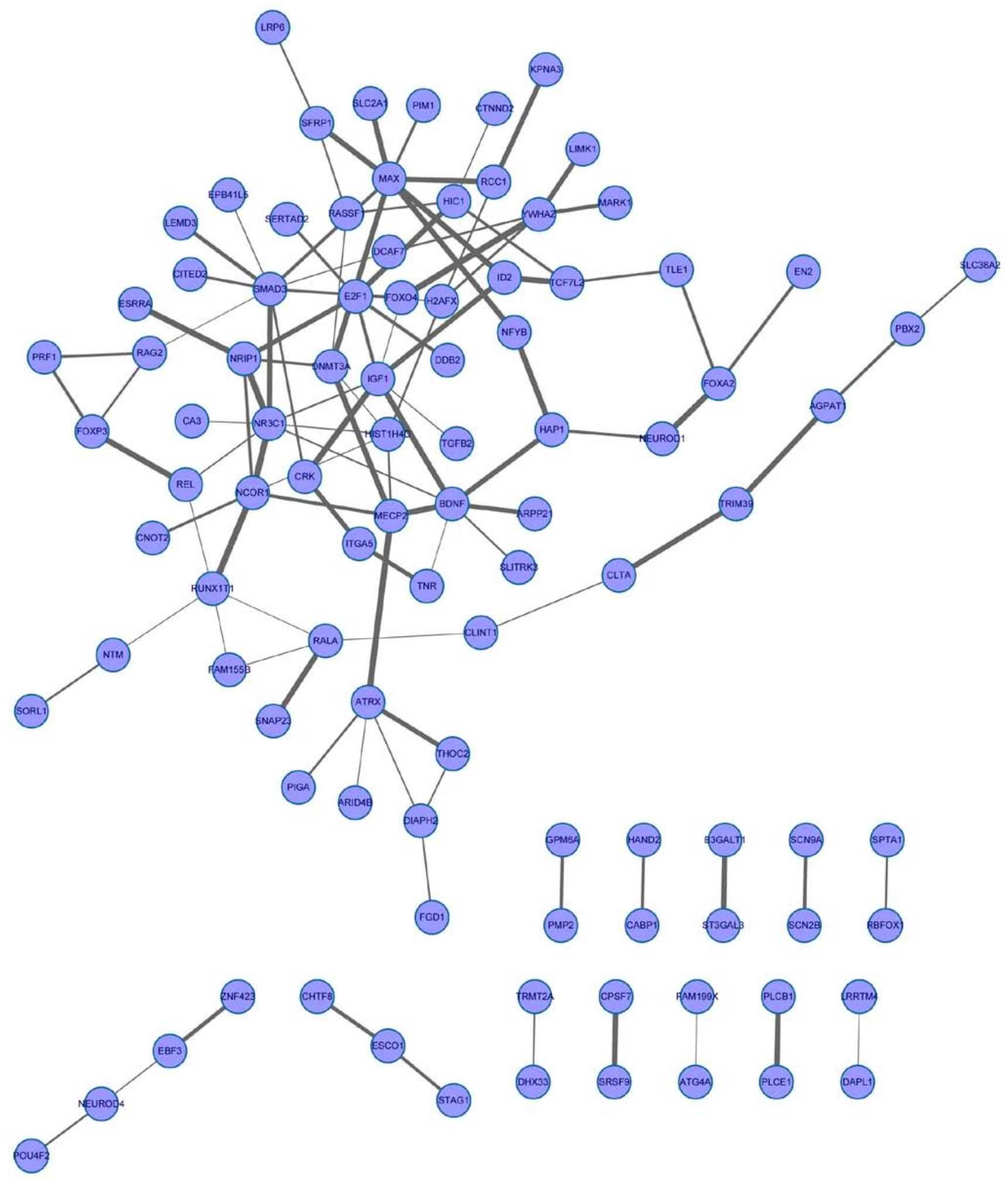

Figure 2. The protein-protein interaction network of target genes of miR-1251, miR-618 and miR-328. Nodes represent target genes; lines represent interactions; the thickness of the line is proportional to the combined score.

(e.g. $M A X$ and SLC2A1) (Table II). Meanwhile, the target genes of hsa-mir-618 were mainly enriched in the GO terms of the negative regulation of transcription from the RNA polymerase II promoter (e.g. E2F1 and ID2) and transcription repressor activity (e.g. $E 2 F 1$ and $I D 2$ ), as well as the TGF- $\beta$ signaling pathway (e.g. ID2 and SMAD3) (Table III). There were no significant GO and pathway terms enriched by the target genes of hsa-mir-1251.

Furthermore, to further reveal the functions of 97 genes in the PPI interaction network, functional clustering and pathway enrichment analysis were performed. According to the functional clustering, 19 clusters were enriched. A set of genes (e.g. 


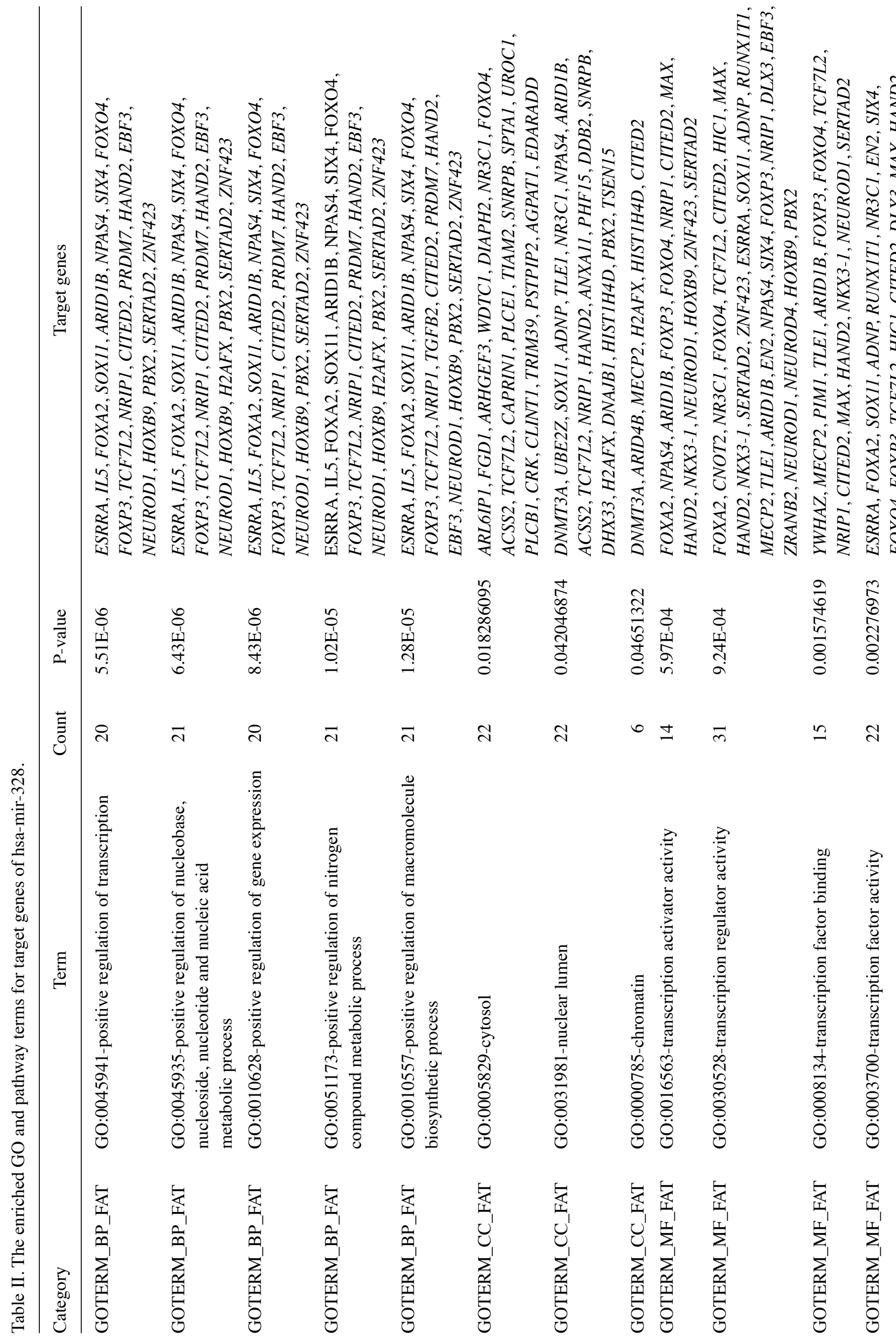


$E 2 F 1, N R 3 C 1, I G F 1, S M A D 3$ and $B D N F$ ) were significantly enriched in multiple functional clusters, such as cell death and signal transduction (Fig. 3). Additionally, 26 genes in the network were markedly enriched in 9 pathway clusters, such as pathways in cancer (e.g. E2F1, MAX and SMAD3), cell cycle (e.g. $E 2 F 1$ and $S M A D 3$ ) and the Wnt signaling pathway (e.g. SMAD3) (Table IV).

\section{Discussion}

HNSCC is a common type of non-skin cancer worldwide (1). In the present study, using the miRNA expression profile and clinical data of 397 cases in the TCGA database, miR-1251, miR-618 and miR-328 were screened out to be significantly associated with risk factors for HNSCC, based on the survival analysis and Cox regression analysis. A set of target genes of these three miRNAs were significantly enriched in a series of GO functions and pathways. For example, targets of miR-618, $E 2 F 1$ and $S M A D 3$, were significantly enriched in functions concerning regulation of transcription, and $S M A D 3$ was also markedly enriched in the TGF- $\beta$ signaling pathway. These two genes interacted with each other in the PPI network.

E2F1 encodes an E2F transcription factor, which mediates cell cycle and functions as a tumor-suppressor protein (23). Overexpression of E2F1 in vitro and in vivo suppresses HNSCC cell growth through induction of apoptosis (24). Additionally, single nucleotide polymorphisms (SNPs) of E2F1 are highly correlated with the risk of HNSCC (25). Moreover, as a transcriptional modulator and signal transducer, $S M A D 3$ mediates multiple signaling pathways and plays a role in the regulation of carcinogenesis (26). In the present study, SMAD3 was predicted to interact with $E 2 F 1$, which has been reported in a previous study (27). In HNSCC, SMAD3 is inactivated, which is associated with higher overall survival of patients (28). In the present study, SMAD3 was markedly enriched in the TGF- $\beta$ signaling pathway. The association of $S M A D 3$ and TGF- $\beta$ signaling has been reported in numerous studies (29-31). A previous study reported that overexpression of death-associated protein kinase-related apoptosis-inducing kinase 1 (DRAKl) binds to Smad3, and then inhibits TGF- $\beta 1$ tumor suppressor activity in HNSCC (32). Additionally, SNPs in miR-618 are implicated in cancer risk (33). miR-618 has been discovered to be progressively expressed in esophageal adenocarcinoma (34). There is no evidence that miR-618 is associated with HNSCC risk or survival rate. Taken together, miR-618 may play a crucial role in the prognosis of HNSCC by regulating the genes $E 2 F 1$ and $S M A D 3$.

Furthermore, in the PPI network, the target gene of miR-328, MAX, interacted with multiple genes, such as E2F1. $M A X$ was significantly enriched in the function of transcription activator activity and the pathways in cancer. MYC associated factor $\mathrm{X}(M A X)$ encodes a transcription factor belonging to the helix-loop-helix leucine zipper (bHLHZ) family (35). It is able to form a homodimer and heterodimer with MYC, which is an oncoprotein correlated with cell proliferation, differentiation and apoptosis (35). There is no evidence to prove the association of MAX with HNSCC. However, overexpression of c-myc has been reported to be associated with the poor prognosis of HNSCC (36). Furthermore, c-myc promotes elevated levels of glutaminolysis and glutamic acid, which marker aggressive 


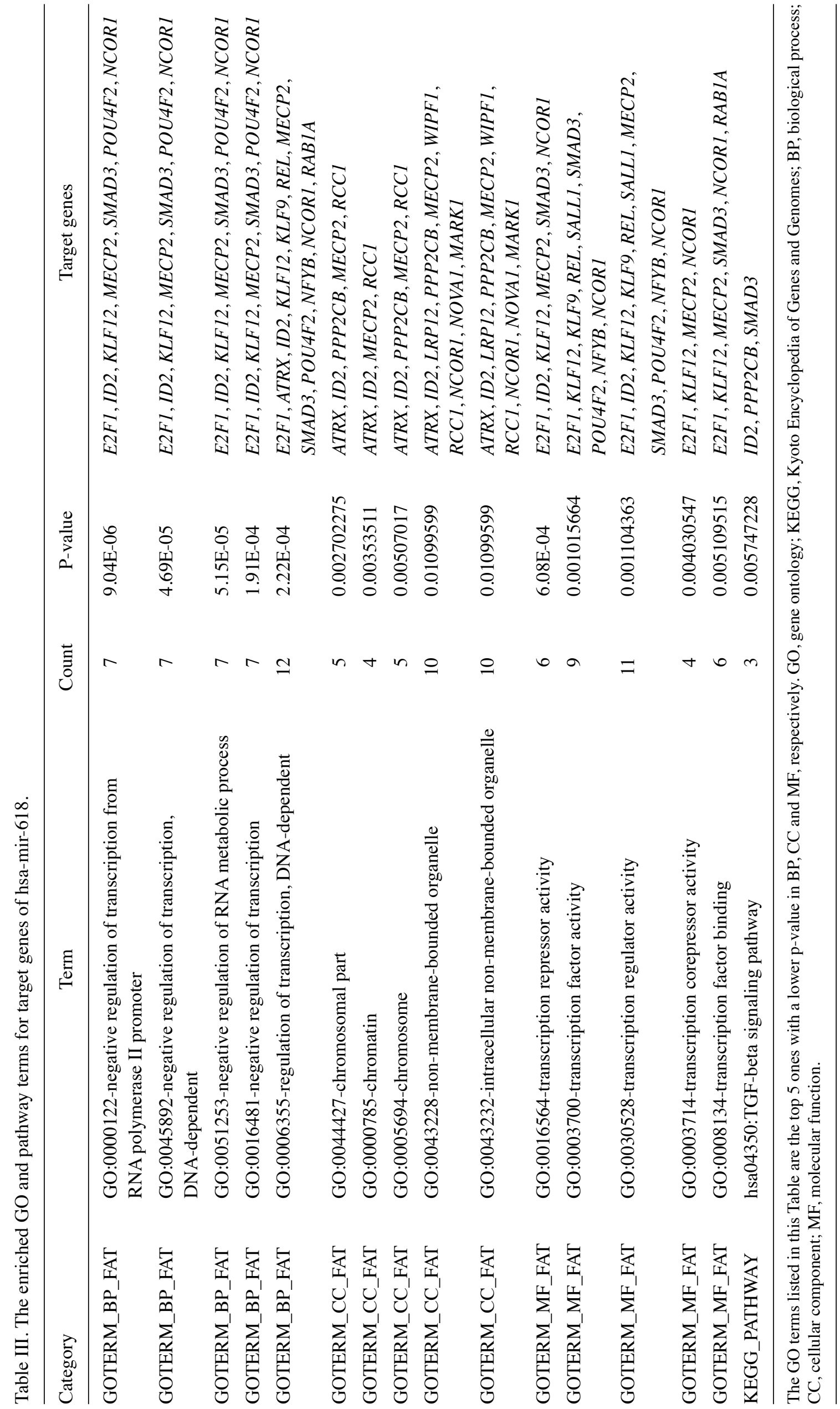




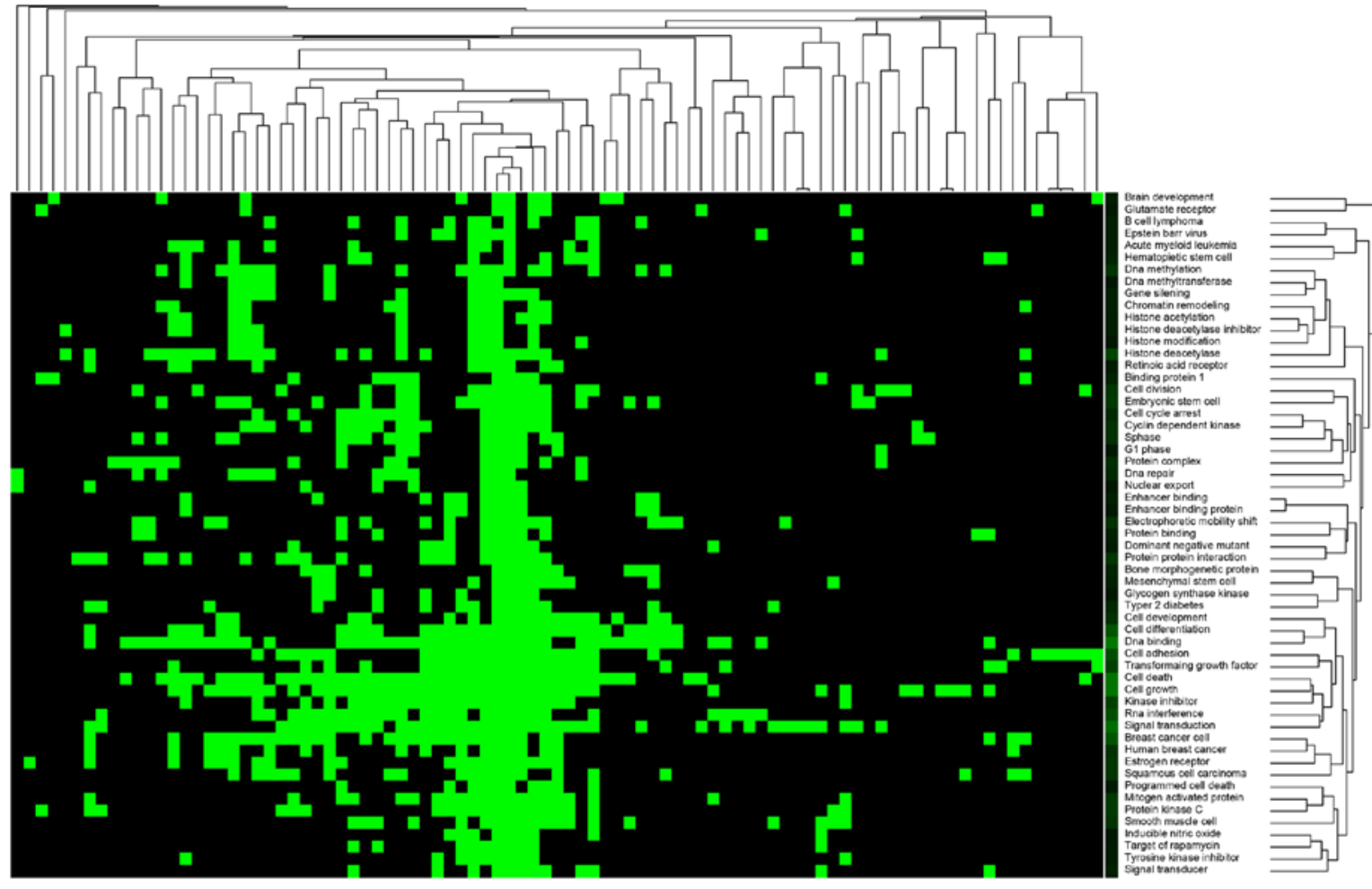

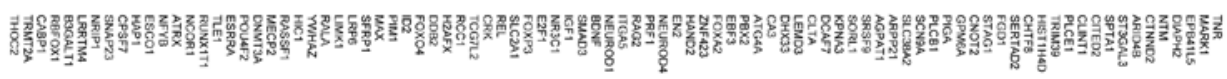

Figure 3. Functional clustering of target genes. Horizontal axis represents target genes; vertical axis represents the terms of function. The color of green represents that genes are related to the functional term, and the color of black represents that genes are not related to the functional term.

Table IV. Enriched pathways of the target genes in the protein-protein interaction network.

\begin{tabular}{|c|c|c|c|c|}
\hline Cluster & Pathway & Count & $\mathrm{P}$-value & Genes \\
\hline \multirow[t]{3}{*}{1} & KEGG_Pathways in cancer & 11 & $3.74 \mathrm{E}-06$ & $\begin{array}{l}C R K, E 2 F 1, I G F 1, M A X, R A L A, R A S S F 1, \\
R U N X 1 T 1, S L C 2 A 1, S M A D 3, T C F 7 L 2, T G F B 2\end{array}$ \\
\hline & KEGG_Chronic myeloid leukemia & 4 & 0.003836 & $C R K, E 2 F 1, S M A D 3, T G F B 2$ \\
\hline & KEGG_Renal cell carcinoma & 3 & 0.023754 & $C R K, S L C 2 A 1, T G F B 2$ \\
\hline \multirow[t]{5}{*}{2} & KEGG_Cell cycle & 5 & 0.000997 & E2F1, SMAD3, STAG1, TGFB2, YWHAZ \\
\hline & BIOCARTA_G1 pathway & 3 & 0.001847 & $E 2 F 1, S M A D 3, T G F B 2$ \\
\hline & KEGG_Pancreatic cancer & 4 & 0.003295 & $E 2 F 1, R A L A, S M A D 3, T G F B 2$ \\
\hline & KEGG_Colorectal cancer & 3 & 0.017246 & SMAD3, TCF7L2, TGFB2 \\
\hline & KEGG_TGF $\beta$ signaling pathway & 3 & 0.039070 & ID2, SMAD3, TGFB2 \\
\hline 3 & KEGG_Acute myeloid leukemia & 3 & 0.013764 & PIM1, RUNX1T1, TCF7L2 \\
\hline 4 & BIOCARTA_PPARA pathway & 3 & 0.014425 & CITED2, NCOR1, NRIP1 \\
\hline \multirow[t]{2}{*}{5} & KEGG_Wnt signaling pathway & 5 & 0.005182 & LRP6, PLCB1, SFRP1, SMAD3, TCF7L2 \\
\hline & Wnt_Signaling & 3 & 0.043830 & $L R P 6, S F R P 1, T L E 1$ \\
\hline \multirow[t]{2}{*}{6} & $\begin{array}{l}\text { REACTOME_Clathrin derived } \\
\text { vesicle budding }\end{array}$ & 3 & 0.016514 & CLINT1, CLTA, SNAP23 \\
\hline & REACTOME_Membrane trafficking & 3 & 0.031420 & CLINT1, CLTA, SNAP23 \\
\hline 7 & ST_Integrin signaling pathway & 3 & 0.031420 & $C R K, I T G A 5, R A L A$ \\
\hline \multirow[t]{2}{*}{8} & $\begin{array}{l}\text { KEGG_Hypertrophic } \\
\text { cardiomyopathy HCM }\end{array}$ & 3 & 0.036795 & $I G F 1, I T G A 5, T G F B 2$ \\
\hline & KEGG_Dilated cardiomyopathy & 3 & 0.045063 & $I G F 1, I T G A 5, T G F B 2$ \\
\hline 9 & KEGG_Prostate cancer & 3 & 0.043830 & $E 2 F 1, I G F 1, T C F 7 L 2$ \\
\hline
\end{tabular}

KEGG, Kyoto Encyclopedia of Genes and Genomes. 
tumorigenesis in HNSCC (37). Additionally, miR-328 has been confirmed to be highly expressed in salinomycin-treated HNSCC cells (38). Additionally, the expression level of miR-328 was found to be significantly higher in early-stage non-small cell lung cancer (NSCLC), and shows good diagnostic accuracy in NSCLC patients (39). These results indicate an important role of miR-328 in cancer. Therefore, miR-328 may play a pivotal role in the progression of HNSCC via targeting $M A X$, and it may be associated with the survival time of HNSCC patients.

In addition, the target gene of miR-1251, IGF1, also interacted with $E 2 F 1$ in the PPI network, and it was enriched in multiple function clusters, such as cell death and signal transduction. Insulin-like growth factor I $(I G F 1)$ is involved in regulating cell growth and development (40), and the activation of multiple signaling pathways in head and neck cancer (41). Previous studies have demonstrated that IGF1 is able to stimulate the expression of vascular endothelial growth factor, which is correlated with increased progression and poor prognosis of HNSCC $(42,43)$. Moreover, miR-1251 has been discovered to be downregulated in nasopharyngeal carcinoma (44). There is no study to report the association of miR-1251 with HNSCC. Therefore, miR-1251 may play a crucial role in the progression of HNSCC via mediating the expression of $I G F 1$, and it may be closely associated with the survival of HNSCC patients.

Despite the aforementioned results, there were several limitations in the present study. The predicted results should be confirmed by laboratory data. In our further studies, the expression levels of miR-1251, miR-618 and miR-328, as well as the regulatory relationships of them and their target genes, will be validated in a large scale of patients with HNSCC.

In conclusion, miR-1251, miR-618 and miR-328 were predicted to be associated with the survival time of HNSCC patients. They may play pivotal roles in the progression of HNSCC via a set of genes associated with transcriptional regulation or signal transduction, such as $M A X, E 2 F 1, S M A D 3$ and $I G F 1$. The three miRNAs were considered as novel prognostic markers in HNSCC. These findings contribute to our further experimental study, and may provide new information for the estimation of the prognosis of HNSCC.

\section{Acknowledgements}

The present study was supported by the Natural Science Foundation of Liaoning Province (no. 201202287).

\section{References}

1. Stransky N, Egloff AM, Tward AD, Kostic AD, Cibulskis K, Sivachenko A, Kryukov GV, Lawrence MS, Sougnez C, McKenna A, et al: The mutational landscape of head and neck squamous cell carcinoma. Science 333: 1157-1160, 2011.

2. Krol J, Loedige I and Filipowicz W: The widespread regulation of microRNA biogenesis, function and decay. Nat Rev Genet 11: 597-610, 2010.

3. Farazi TA, Hoell JI, Morozov P and Tuschl T: MicroRNAs in Human Cancer. In: MicroRNA Cancer Regulation, Advanced Concepts, Bioinformatics and Systems Biology Tools. Schmitz U, Wolkenhauer O and Vera J (eds.). Springer, pp1-20, 2013.

4. Kinoshita T, Hanazawa T, Nohata N, Kikkawa N, Enokida H, Yoshino H, Yamasaki T, Hidaka H, Nakagawa M, Okamoto Y, et al: Tumor suppressive microRNA-218 inhibits cancer cell migration and invasion through targeting laminin-332 in head and neck squamous cell carcinoma. Oncotarget 3: 1386-1400, 2012.
5. Jimenez L, Sharma VP, Lim J, Angeletti R, Condeelis J, Harris T, Prystowsky MB, Childs G and Segall JE: MicroRNA-375 impairs head and neck squamous cell carcinoma invasion by suppressing invadopodia activity. Cancer Res 74: 1452, 2014. doi:10.1158/1538-7445.AM2014-1452

6. Jimenez L, Harris T, Kawachi N, Belbin T, Schlecht N, Lim J, Angeletti R, Prystowsky MB, Childs G and Segall J: MicroRNA-375 regulates tumor invasion and metastasis phenotypes and is associated with poor outcome in head and neck squamous cell carcinoma. Cancer Res 73: 4939, 2013. doi:10.1158/1538-7445.AM2013-4939.

7. Langevin SM, Stone RA, Bunker $\mathrm{CH}$, Lyons-Weiler MA LaFramboise WA, Kelly L, Seethala RR, Grandis JR, Sobol RW and Taioli E: MicroRNA-137 promoter methylation is associated with poorer overall survival in patients with squamous cell carcinoma of the head and neck. Cancer 117: 1454-1462, 2011.

8. Howard JD, Cheng H, Ratner E, Fertig EJ, Perez J, Quon H, Considine M, Ochs $\mathrm{M}$, Weidhaas $\mathrm{J}$ and Chung $\mathrm{CH}$ : MicroRNA profiling reveals miR-205 upregulation is associated with head and neck squamous cell carcinoma and modulates E2F1 signaling. Cancer Res 73 (Suppl 8): 3100-3100, 2013.

9. Therneau TM: Modeling survival data. In: Extending the Cox Model. Springer, 2000. http://dx.doi.org/10.1007/978-14757-3294-8.

10. Timsit JF, Alberti C and Chevret S: Cox proportional hazards regression analysis. Rev Mal Respir 22: 1058-1064, 2005 (In French)

11. Ferguson N, Datta S and Brock G: msSurv, an R package for nonparametric estimation of multistate models. J Stat Software 50: 1-24, 2012.

12. Piriyapongsa J, Bootchai C, Ngamphiw C and Tongsima S: microPIR: An integrated database of microRNA target sites within human promoter sequences. PLoS One 7: e33888, 2012.

13. Dweep H, Sticht C, Pandey P and Gretz N: miRWalk - database: Prediction of possible miRNA binding sites by 'walking' the genes of three genomes. J Biomed Inform 44: 839-847, 2011.

14. Enright AJ, John B, Gaul U, Tuschl T, Sander C and Marks DS: MicroRNA targets in Drosophila. Genome Biol 5: R1-R1, 2003.

15. Wang $X$ and El Naqa IM: Prediction of both conserved and nonconserved microRNA targets in animals. Bioinformatics 24: 325-332, 2008.

16. Krek A, Grün D, Poy MN, Wolf R, Rosenberg L, Epstein EJ, MacMenamin P, da Piedade I, Gunsalus KC, Stoffel M, et al: Combinatorial microRNA target predictions. Nat Genet 37: 495-500, 2005.

17. Thomas M, Lieberman $\mathrm{J}$ and Lal A: Desperately seeking microRNA targets. Nat Struct Mol Biol 17: 1169-1174, 2010.

18. Lewis BP, Shih IH, Jones-Rhoades MW, Bartel DP and Burge CB: Prediction of mammalian microRNA targets. Cell 115: 787-798, 2003.

19. Franceschini A, Szklarczyk D, Frankild S, Kuhn M, Simonovic M, Roth A, Lin J, Minguez P, Bork P, von Mering C, et al: STRING v9.1: Protein-protein interaction networks, with increased coverage and integration. Nucleic Acids Res 41: D808-D815, 2013.

20. Smoot ME, Ono K, Ruscheinski J, Wang PL and Ideker T: Cytoscape 2.8: New features for data integration and network visualization. Bioinformatics 27: 431-432, 2011.

21. Huang W, Sherman BT and Lempicki RA: Systematic and integrative analysis of large gene lists using DAVID bioinformatics resources. Nat Protoc 4: 44-57, 2009.

22. Huang ZX, Tian HY, Hu ZF, Zhou YB, Zhao J and Yao KT: GenCLiP: A software program for clustering gene lists by literature profiling and constructing gene co-occurrence networks related to custom keywords. BMC Bioinformatics 9: 308, 2008.

23. Ting JH: Novel roles of cell cycle regulator E2F1 in the CNS: Implications for synaptic damage in HIV-associated neurocognitive disorders. University of Pennsylvania, Scholarly Commons: Publicly Accessible Penn Dissertations. Paper 1471, 2014. http:// repository.upenn.edu/edissertations/1471.

24. Liu TJ, Wang M, Breau RL, Henderson Y, El-Naggar AK, Steck KD, Sicard MW and Clayman GL: Apoptosis induction by E2F-1 via adenoviral-mediated gene transfer results in growth suppression of head and neck squamous cell carcinoma cell lines. Cancer Gene Ther 6: 163-171, 1999.

25. Lu M, Liu Z, Yu H, Wang LE, Li G, Sturgis EM, Johnson DG and Wei Q: Combined effects of $E 2 F 1$ and $E 2 F 2$ polymorphisms on risk and early onset of squamous cell carcinoma of the head and neck. Mol Carcinog 51 (Suppl 1): E132-E141, 2012. 
26. Murata M, Yoshida K and Matsuzaki K: Early chronic inflammation and subsequent somatic mutations shift phospho-Smad3 signaling from tumor-suppression to fibro-carcinogenesis in human chronic liver diseases. In: Hepatocellular CarcinomaFuture Outlook. Kaseb A (Ed.). InTech 2013: DOI: 10.5772/ 56739. Available from: http://www.intechopen.com/books/hepatocellular-carcinoma-future-outlook/early-chronic-inflammation -and-subsequent-somatic-mutations-shift-phospho-smad3-signaling-from-tumor.

27. Kowalik TF: Smad about E2F. TGFbeta repression of $c-M y c$ via a Smad3/E2F/p107 complex. Mol Cell 10: 7-8, 2002.

28. Xie W, Aisner S, Baredes S, Sreepada G, Shah R and Reiss M Alterations of Smad expression and activation in defining 2 subtypes of human head and neck squamous cell carcinoma. Head Neck 35: 76-85, 2013.

29. Derynck R and Zhang YE: Smad-dependent and Smadindependent pathways in TGF- $\beta$ family signalling. Nature 425 : 577-584, 2003.

30. Massagué J and Wotton D: Transcriptional control by the TGF- $\beta$ /Smad signaling system. EMBO J 19: 1745-1754, 2000.

31. Heldin $\mathrm{CH}$, Miyazono K and ten Dijke P: TGF- $\beta$ signalling from cell membrane to nucleus through SMAD proteins. Nature 390: 465-471, 1997.

32. Park Y, Kim W, Lee J, Park J, Cho JK, Pang K, Lee J, Kim D, Park SW, Yang KM et al: Cytoplasmic DRAK1 overexpressed in head and neck cancers inhibits TGF- $\beta 1$ tumor suppressor activity by binding to Smad3 to interrupt its complex formation with Smad4. Oncogene 34: 5037-5045, 2015.

33. Pelletier $\mathrm{C}$ and Weidhaas JB: MicroRNA binding site polymorphisms as biomarkers of cancer risk. Expert Rev Mol Diagn 10 $817-829,2010$.

34. Wu X, Ajani JA, Gu J, Chang DW, Tan W, Hildebrandt MA, Huang M, Wang KK and Hawk E: MicroRNA expression signatures during malignant progression from Barrett's esophagus to esophageal adenocarcinoma. Cancer Prev Res 6: 196-205, 2013.

35. Blackwood EM and Eisenman RN: Max: A helix-loop-helix zipper protein that forms a sequence-specific DNA-binding complex with Myc. Science 251: 1211-1217, 1991.
36. Field JK, Spandidos DA, Stell PM, Vaughan ED, Evan GI and Moore JP: Elevated expression of the c-myc oncoprotein correlates with poor prognosis in head and neck squamous cell carcinoma. Oncogene 4: 1463-1468, 1989.

37. Banda AD, Cortes MB, Kamarajan P, Rajendiran T, Chinnaiyan AM and Kapila YL: Glutamic acid and glutaminolysis mark aggressive tumorigenesis in head and neck squamous cell carcinoma. Cancer Res 75 (Suppl 15): 1192, 2015.

38. Kuo SZ, Blair KJ, Rahimy E, Kiang A, Abhold E, Fan JB, Wang-Rodriguez J, Altuna X and Ongkeko WM: Salinomycin induces cell death and differentiation in head and neck squamous cell carcinoma stem cells despite activation of epithelial-mesenchymal transition and Akt. BMC Cancer 12: 556, 2012.

39. Ulivi P, Foschi G, Mengozzi M, Scarpi E, Silvestrini R, Amadori D and Zoli W: Peripheral blood miR-328 expression as a potential biomarker for the early diagnosis of NSCLC. Int J Mol Sci 14: 10332-10342, 2013.

40. Woods KA, Camacho-Hübner C, Savage MO and Clark AJ: Intrauterine growth retardation and postnatal growth failure associated with deletion of the insulin-like growth factor I gene. N Engl J Med 335: 1363-1367, 1996.

41. Rosenzweig SA and Holmes CO: Insulin-like growth factor-1 receptors in head and neck cancer. In: Molecular Determinants of Head and Neck Cancer. Springer, pp113-130, 2014.

42. Slomiany MG, Black LA, Kibbey MM, Day TA and Rosenzweig SA: IGF-1 induced vascular endothelial growth factor secretion in head and neck squamous cell carcinoma. Biochem Biophys Res Commun 342: 851-858, 2006.

43. Jameson MJ, Beckler AD, Taniguchi LE, Allak A, Vanwagner LB, Lee NG, Thomsen WC, Hubbard MA and Thomas CY: Activation of the insulin-like growth factor-1 receptor induces resistance to epidermal growth factor receptor antagonism in head and neck squamous carcinoma cells. Mol Cancer Ther 10: 2124-2134, 2011.

44. Plieskatt JL, Rinaldi G, Feng Y, Levine PH, Easley S, Martinez E, Hashmi S, Sadeghi N, Brindley PJ, Bethony JM, et al: Methods and matrices: Approaches to identifying miRNAs for nasopharyngeal carcinoma. J Transl Med 12: 3, 2014. 